Please cite as: Kersten P, McPherson K, Lattimer V, George S, Breton A, Ellis B (2007). Physiotherapy extended scope of practice - who is doing what and why? Physiotherapy. 93:235-242

\title{
Title: Physiotherapy extended scope of practice - who is doing what and why?
}

Paula Kersten $^{\mathrm{a}}$, Kath McPherson ${ }^{\mathrm{a}}$, Val Lattimer ${ }^{\mathrm{b}}$, Steve George ${ }^{\mathrm{c}}$, Alice Breton ${ }^{\mathrm{d}}$, Bridget Ellis ${ }^{\mathrm{e}}$

${ }^{a}$ Paula Kersten, BSc (Physiotherapy), MSc Rehabilitation Studies, PhD

School of Health Professions and Rehabilitation Sciences

University of Southampton

United Kingdom

P.Kersten@soton.ac.uk

${ }^{a}$ Kathryn McPherson, RN, RM, DipHV, BA(Hons), PhD

School of Health Professions and Rehabilitation Sciences, University of Southampton,

United Kingdom

\&

Physical Rehabilitation Research Centre

AUT University

Auckland

${ }^{\mathrm{b}}$ Val Lattimer, RGN, MA Ed, PhD

School of Nursing and Midwifery

University of Southampton

United Kingdom

V.A.Lattimer@soton.ac.uk

${ }^{\mathrm{c}}$ Steve George MD, MSc, FRCP, FFPH(M)

Public Health Sciences and Medical Statistics

School of Medicine,

University of Southampton

United Kingdom

Pluto@soton.ac.uk

${ }^{\mathrm{d}}$ Alice Breton, BSc, NZCLS, MA

Royal College of Surgeons

Edinburgh

Alice.Breton@,RCSED.AC.UK

${ }^{\mathrm{e}}$ Bridget Ellis, Diploma in Physiotherapy, MSc

Physiotherapy Department,

Poole Hospital NHS Trust 
United Kingdom

Bridget.Ellis@poole.nhs.uk

United Kingdom

Corresponding author:

Paula Kersten, PhD

Senior Lecturer

School of Health Professions and Rehabilitation Sciences

Building 45

University of Southampton

SO17 1BJ

United Kingdom

Phone: +44 2380595299

Fax: +44 2380595301

P.Kersten@hotmail.co.uk 


\section{$\underline{\text { Abstract }}$}

Objectives: To explore the range, drivers and perspectives of extended or enhanced practitioner roles within physiotherapy.

Data sources: Nineteen electronic databases, hand searches, bibliography scanning and personal contact were used to identify published and unpublished resources.

\section{Review methods:}

A systematic review using an expanded approach. Resources were included if they discussed extended scope of practice (ESP, intervention) in physiotherapy (profession) and outcome (for patients, other health professionals, and health services delivery) irrespective of patient group, language, year of publication (up to 2005), study design, or health care systems evaluated. All resources were screened against formal inclusion criteria for relevance. Information from relevant resources was extracted and details were entered into an Access database.

\section{Results:}

152 Physiotherapy-related resources were identified, including seven which met appropriate quality standards (using Cochrane methodology). A meta-analysis was not performed due to the paucity of RCTs.

\section{Conclusions}

Drivers for the roles in the 152 resources mainly included local or national service demands (34\%). Most ESP roles reported included a form of non-invasive assessment $(47 \%)$ or non-invasive treatment $(37 \%)$ of patients that was more traditionally carried out by medical colleagues. None of the resources including data were a) unsupportive of ESP or b) mainly expressing concerns. This review has demonstrated overwhelming support 
for ESP; the vast majority of resources were supportive of ESP despite being largely descriptive or discursive in nature (76\%). There is an urgent need for robust research in order to evaluate the expansion of ESP roles, underpin further development of those roles and, strengthen the evidence base of ESP in physiotherapy.

\section{Keywords}

Physiotherapy, Extended Scope of Practice, systematic review 


\section{Background}

Many drivers for workforce re-configurations in the UK are driven by politics and economics. For example, the introduction of the New Deal European Working Time Directive(1) has resulted in reduced hours for junior medical staff and this has necessitated the need to redistribute tasks traditionally carried out by doctors to non-medical members of the health care team in the United Kingdom (UK). Policy documents such as the "Meeting the challenge: a strategy for the allied health professions", "Ten Key Roles for allied health professionals" and "Creating a Patient-led NHS: Delivering the NHS Improvement Plan" all set out the direction for more flexible working and workforce reconfigurations.(2-4) As a result we have seen the introduction of nurse practitioners, extended scope practitioners (ESP) and consultant practitioners in a range of therapy professions within the UK. In physiotherapy especially, new roles in extended scope of practice have rapidly been taken up.(5) Defining extended scope of practice is complicated, however, due to the different nature of the roles and ambiguous definition. For example, some therapists work in extended roles but do not necessarily carry the title of ESP. Titles used include clinical specialists, advanced practitioners and consultant therapists (although by no means do these all work outside their scope of practice). The Chartered Society of Physiotherapists suggests that ESPs are:

'clinical physiotherapy specialists in any recognised speciality with an extended scope of practice'(6) 
However, with changing roles the scope of practice inevitably changes and extended scope can become established practice. A useful definition of extended scope of practice could also include the terms "role enhancement" or "role substitution".(7)

Role Enhancement: increasing the depth of a job by extending the role or skills of a particular group of workers

Role Substitution: expanding the breadth of a job in particular, by working across professional divides or exchanging one type of worker for another.

In physiotherapy, examples of role enhancement include the use of injection therapy $(8)$ and role substitution include physiotherapists working in out-patient clinics carrying out patient assessments traditionally carried out by medically qualified personnel.(9)

Although extended scope of practice within UK government policy is strongly promoted for allied health professionals, including physiotherapy, $(3 ; 4 ; 10)$ systematic evaluation of these roles and their effect is scarce. Indeed, findings from a recent systematic review which aimed to synthesise evidence for effectiveness of extended scope practice in allied health (11) resulted in only seven physiotherapy-related resources $(8 ; 9 ; 12-16)$ that passed quality filters (based on the rigour of the design and other recognised characteristics of robust research). Each of these seven resources focused on services for patients with musculoskeletal conditions. Key findings from the only trial showed that orthopaedic physiotherapy specialists were as effective as junior orthopaedic surgeons in the initial assessment and management of new referrals to outpatient orthopaedic departments.(9) A 
key focus of most studies was that physiotherapists had expanded their roles to increase their professional autonomy and skills, although service demands were more frequently reported by doctors as drivers for the development of these innovative roles.(13-15) Concerns were expressed about litigation, lack of confidence and fear of adverse reactions when using injection skills, variations in training, and the notion that the ESP service is 'only as good as the therapist employed' $(8 ; 14 ; 16)$ and one study suggested that being an ESP can be both stressful and satisfying.(12) In summary, this recent systematic review showed that evidence about the effectiveness of physiotherapy ESP is very limited and further research is needed to ensure patients are cared for most effectively. The review also aimed to define the range of extended or enhanced practitioner roles within allied health. Thus, rather than focusing on trials and other studies which passed quality filters only it was deemed important to scope and summarise descriptively (without drawing conclusions about evidence for effectiveness) what the state of affair was in ESP physiotherapy. This is important as the profession needs to understand what the drivers are for role development, the nature of the ESP roles (e.g. what patient groups are worked with and what interventions are included) and perspectives of the roles. This paper therefore aims to explore the range of extended or enhanced practitioner roles within physiotherapy using all the resources retrieved in the systematic review described above (11). The definition for ESP used in this review was 'AHP activity including some aspect of Enhancement or Substitution' although a very broad search strategy was used to identify resources. 


\section{Methods}

This systematic review consisted of two phases (Figure 1). In phase 1 all resources relevant to physiotherapy ESP were identified and summarised descriptively (described here); in phase 2 resources with data were quality rated using a Cochrane approach and data were extracted from resources which passed these quality criteria (described in detail in a previous publication)(11).

An expanded approach to the review methodology was employed for the study as it was important to consider all resources for this part of the study. Therefore literature was included irrespective of language, year of publication, study design, or health care systems evaluated. Published and unpublished materials literature were included.

The literature search employed a three-part search strategy framework of a) patients (any patient group)/professions (physiotherapy), b) intervention (extended scope of practice) and c) outcome (for patients, other health professionals, and health services delivery).(17) This comprehensive search strategy used a combination of MeSH terms for professions (physiotherapy) and interventions (ESP) and keywords (Appendix 1). In addition, an abbreviated version was developed for use with databases that do not provide nesting of search terms through use of multiple Boolean operators. A wide range of sources were used (Table 1). Studies that were published in duplicate were included only once. In the case of papers or reports being linked to other work, such links were noted and reflected in the database. 
Insert Table 1 about here

The formal data collection period ran until June 2004 with periodic checks for key source updates until December 2004. A final update of research literature only was conducted for work published in 2005. Information obtained in the review was imported and managed in Reference Manager Version 10 (Network Version) and Access 2002.

All resources were screened for relevance against formal inclusion criteria by one reviewer after inter-rater reliability was established.(11) Resources were included if they concerned physiotherapy, extended scope of practice and addressed the impact of ESP in its widest sense (Figure 2).

All relevant resources and those where there was any doubt raised by the first reviewer, were screened independently by a second reviewer to minimise selection bias. As this paper aims to describe our understanding of the drivers and processes of role development and aspects of the roles themselves all relevant resources $(n=152)$ were included, irrespective of the presence of data. Information from relevant resources was extracted and details were entered into an Access database.

Resources containing research data were subsequently quality rated, using Cochrane methodology.(18;19) Data from those resources that passed the quality criteria were synthesised. This included seven physiotherapy research papers, which have been 
summarised above and published previously. (11) These are also included within this paper.

Whilst the remaining resources cannot be relied upon for 'evidence' of the impact of ESP they do indicate the support, or lack of it, for these roles. Therefore all 152 resources were grouped into six categories:
A Evidence (but limits to that evidence) to support ESP is provided
B Largely descriptive / discursive but author(s) supportive of ESP
C Evidence (with some methodological problems) that ESP should not be supported
D Largely descriptive /discursive author(s) express concerns or are not supportive of ESP
E Largely descriptive /discursive author(s) express partial support but also concerns F Largely descriptive /discursive author(s) express mainly concerns

\section{Results}

In total 152 physiotherapy-related resources were identified ( 8 resources pre 1994; 40 resources 1994-1999; 104 resources 2000-2003). A full reference list can be obtained from the authors and is also available on the web).(20) Most resources described local audits $(n=47,31 \%)$ and service descriptions $(n=17,11 \%$, Table 2$)$. The large majority of these audits did not set service standards prior to the audit. In addition, although some audits included a focus on patient satisfaction few explored other patient outcomes (such as impairment/disability level or health status). 
Insert Table 2 about here

The majority of resources found described initiatives or developments in the UK $(n=135$, $89 \%)$ or the USA ( $\mathrm{n}=12,8 \%)$. Most authors did not specifically state the drivers for ESP developments $(\mathrm{n}=71,47 \%)$. Drivers that were noted included local or national service demands ( $\mathrm{n}=51,34 \%)$ such as shortage of doctors or increasing waiting lists. Relatively few explicitly stated improving patient outcomes or service quality $(n=11,7 \%)$ or ensuring patient and practitioner safety as important $(n=3,2 \%)$. The largest group of papers concerned patients with musculoskeletal or orthopaedic disorders $(n=100,66 \%)$. Resources related to other patient groups (e.g. general trauma, minor injuries, rheumatology, cardiorespitratory or neurology) were very small in number (i.e. 8 in total).

The most frequent type of ESP reported included a form of non-invasive assessment $(\mathrm{n}=71,47 \%)$ or non-invasive treatment $(\mathrm{n}=56,37 \%)$ of patients that was more traditionally carried out by medical colleagues. Invasive assessment and treatment were less commonly reported. Table 3 summarises the number of each type of ESP where it was reported to be either definitely or possibly occurring and examples of each.

Insert Table 3 about here 
The vast majority of resources were supportive of ESP despite being largely descriptive or discursive in nature (Category A, 76\%, Table 4). For example, one study described multidisciplinary clinics run by general practitioners with special interests and extended scope physiotherapists.(21) The ESPs were reported to effectively manage patients with uncomplicated musculoskeletal problems. However, this study had methodological limitations and it was not a randomised controlled trial. Its conclusions were therefore premature. In Category B (largely descriptive / discursive work in which author(s) are supportive of ESP) one study involved an orthopaedic screening service run by two physiotherapists with an extended scope of practice.(22) The publication described an evaluation of the service using routine data and found reduced waiting times and need for referral to consultants in only $17 \%$ of cases. However, successful management of the remainder patients was not adequately measured and patients' views were not explored. No resources were identified which included data and did not support ESP (category C) or resources in which the authors expressed mainly concerns about ESP (category F). Two largely descriptive or discursive resources were identified in which author(s) expressed concerns or were not supportive of ESP (Category D). One of these was an opportunistic audit that demonstrated lack of consistency in management of acute low back pain in primary care.(23) This could have been due to changing and/or conflicting National Guidelines for referral, confusion regarding the referral criteria to secondary care, or lack of easy GP access to primary care physiotherapy. Finally, an example of Category E (largely descriptive /discursive in which author(s) express partial support but also concerns) was a questionnaire survey of a small group of extended scope practitioners of their views on prescribing.(24) The majority reported positively. 
However, problems associated with prescribing were highlighted such as competence, supervision, legal and insurance implications and training. The methodology was not described adequately and conclusions can therefore not be drawn from this descriptive account

Insert Table 4 about here

\section{Discussion}

This study used an expanded Cochrane approach and as a result identified a large number of resources which did not use a randomised controlled trial methodology as well as resources that did not describe primary or secondary research. This approach was undertaken after early investigation indicated that there would be insufficient papers using a "gold standard" RCT methodology to undertake a traditional systematic review and to ensure comprehensive coverage of the literature. Whilst this approach may be criticised by some, and indeed led to a large data set for consideration, it enabled us to identify what ESP practices are current, what drives these developments and the level of support for the roles. We have shown caution in this approach by not drawing unsupported or premature conclusions about the effectiveness of interventions.

Since this study was completed three relevant papers were identified in the literature: one retrospective audit, a patient satisfaction survey and a survey of notes.(25-27) Only one of these studies compared treatment provided by an ESP and other professionals and this study was the first to describe an ESP service in an emergency department.(26) It was 
shown that $55 \%$ of patients were independently managed by the ESP and a follow-up suggested higher patient satisfaction with the ESP service. However, the study had significant limitations in that only one ESP was included in the study, it used a retrospective design, patients were not randomised and the response rate was low. Thus, these three newer papers do not add new information than that provided in the results section of our study.

A striking finding of our study was that the number of resources in favour of ESP developments far outnumbered those that expressed negative findings or concerns. Some of this may reflect publication bias. However, it is of concern that $76 \%$ of resources were supportive of ESP yet were largely descriptive or discursive, or did not use robust research methods. The lack of robust research brings into question the rapid development of roles without evidence of their effectiveness, competence or safety. For example, one publication concluded that 'multidisciplinary clinics run by general practitioners with special interests and extended scope physiotherapists can effectively manage patients with uncomplicated musculoskeletal problems'.(21) This study reported reduced waiting times and increased satisfaction. These are indeed positive outcomes in relation to efficiency. However, the conclusion that ESP interventions are safe or effective options for patients is premature. Randomised controlled trials in ESP are limited by the number of staff involved in the service to be evaluated or compared. For example, trials in physiotherapy and radiography have evaluated outcomes in many patients or patients' radiographs but only included very small numbers of staff.(9;28) Since neither interventions nor staff expertise in these studies are standardised it is not possible to conclude that extended scope of practice is effective based on these trials only. Research 
in complex interventions such as extended scope of practice roles should follow stringent guidelines, for example as set out by the Medical Research Council.(29) This ensures that interventions are developed appropriately and that subsequent research is well designed and comparable. Unfortunately, the pace of developments driven by policy initiatives often precedes research and enthusiasm of professional staff often precludes it.

Papers containing data, whether or not passing the quality filters, focused largely on physiotherapy for people with musculoskeletal conditions (e.g. orthopaedic clinics, triage clinics, hand therapy) perhaps unsurprisingly given the preponderance of physiotherapy audits regarding back pain and other orthopaedic conditions. The lack of research about ESP roles in other areas (e.g. neurology, respiratory or emergency care) is of concern given these are areas where ESP is developing rapidly.

On reviewing the relatively large number of UK-based audits, it was found that many were not conducted as proper audit cycles. As a result, the information is of limited value and, in addition, the level of skill of the authors in performing audits must be questioned. Further, there were a large number of resources containing data but which did not pass the quality criteria for data extraction. These papers are nevertheless widely cited both by authors and organisations as 'evidence' when clearly questions about the strength of that evidence remain. It appears that these roles are as yet largely justified and supported based on poorly conducted audit and research which is of concern in terms of patient safety. The findings suggest that therapists need training in research and audit methods. 
Increasingly physiotherapy ESPs work in very different settings. For specific interventions they follow training such as injection therapy. However, the literature reviewed suggests that there is often a lack of support and ad hoc training.(12;13) This is different from other professionals such as paramedics and radiographers for whom extended roles often include the use of defined clinical skills such as thrombolysis(30) or interpreting radiographs. $(31 ; 32)$ Formal training in these professions is a prerequisite to undertaking an extended role. $(33 ; 34)$ Perhaps the physiotherapy profession should follow this example to ensure quality care for patients and regulation and protection for practitioners. In this respect the increasing number of courses for extended scope practitioners in this country is encouraging.

\section{Conclusions}

This review has highlighted that the evidence of effectiveness or safety for ESP in physiotherapy is not sufficient. Despite the lack of robust research and evidence there is overwhelming support for physiotherapy ESP in the literature. Further, the widespread introduction of ESP roles in physiotherapy has been largely concerned with service demands as opposed to quality of care, patient-related outcomes or cost implications. It is paramount that the expansion of ESP roles, driven by policy $(3 ; 4)$, goes hand in hand with robust research in order to strengthen the evidence base for ESP in physiotherapy. Investment in training for therapists entering into and developing these roles is urgently required to ensure that they are equipped to practice safely and have the skills to evaluate their effectiveness. 


\section{Acknowledgements}

The research team would like to thank the contribution of individual practitioners

submitting their work. In addition the team would like to acknowledge the contribution of the Steering Committee. Whilst that contribution has influenced aspects of the design of the project, responsibility for the study findings and the interpretation of those rests with the study team. Thanks also go to Dawn Kaur, Geoff Frampton, Veronika Zihl, Anya Kaushik, and Claudia Fellmer who also assisted in aspects of the review.

Funding: The study was funded by the The NHS Service Delivery and Organisation (SDO) Programme.

\section{Conflict of interest: None}




\section{Figure 1 Study design}

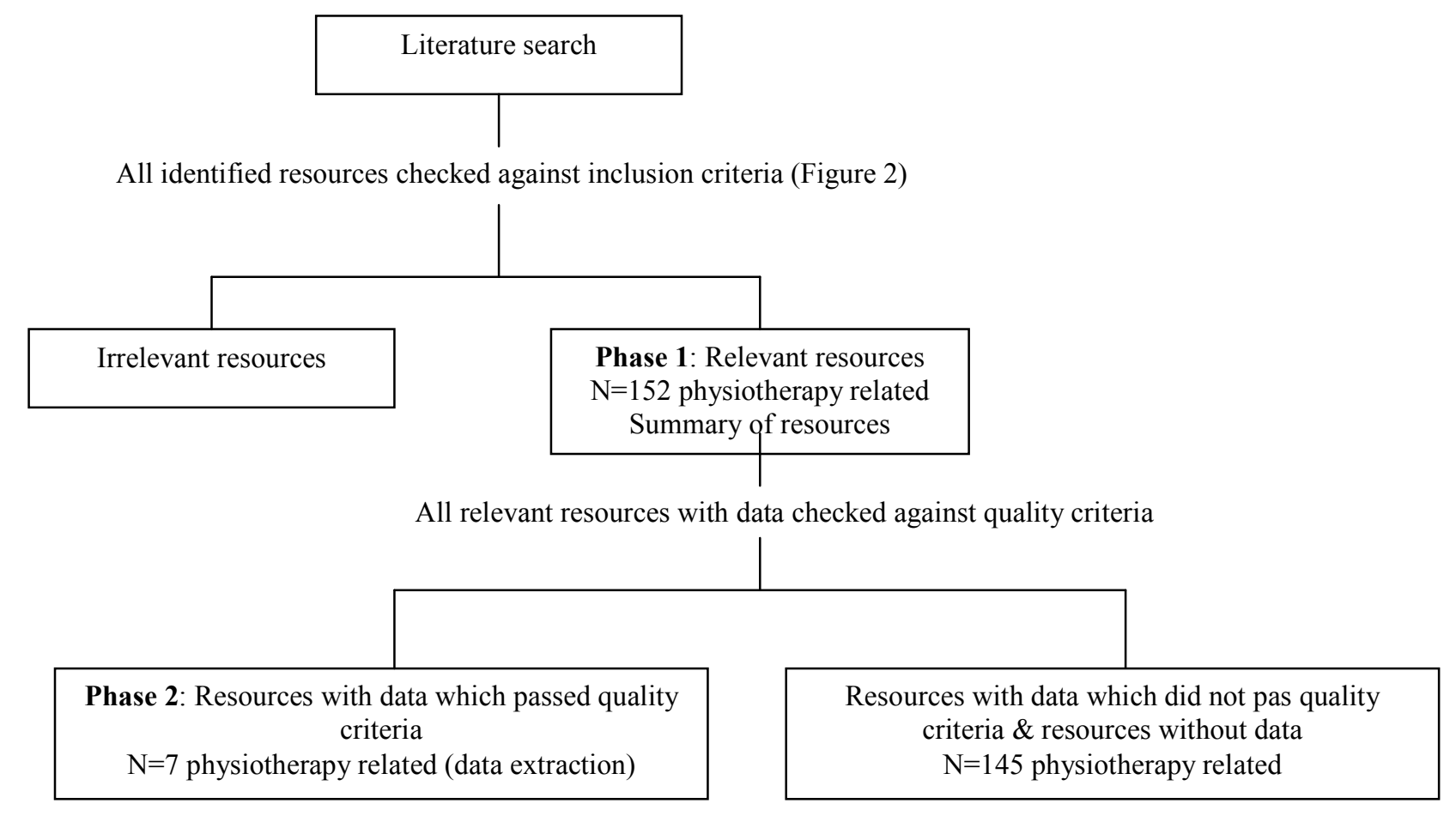




\section{Figure 2 Inclusion and exclusion criteria}

PHASE 1: A1. Population - Does the paper concern physiotherapy?

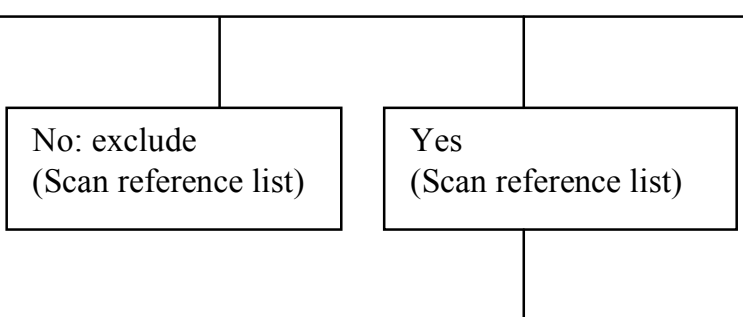

A2. Intervention

a) Does the paper concern role enhancement (new skill/action)?

b) Does the paper concern role substitution (taking role of another)?

c) Does the paper concern some other form of ESP (neither a or b)?

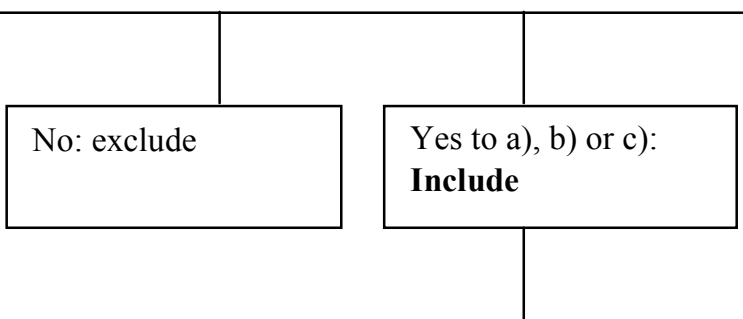

A3. Outcome (includes satisfaction and perception of role)

Does the paper address the impact of ESP on:

a) patients ?

b) the profession concerned ?

c) other professions ?

d) the NHS ?

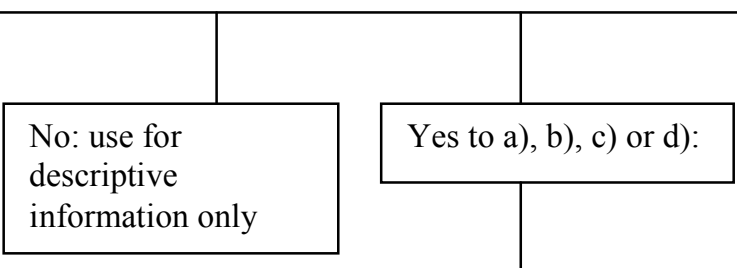

A4. Does the paper report any data (either qualitative or quantitative)?

No: use for descriptive

information only

Yes: proceed to quality screening (phase 2) 
Table 1 Sources used in the search strategy

\begin{tabular}{|c|c|}
\hline \multicolumn{2}{|l|}{ Sources used } \\
\hline Electronic sources: & $\begin{array}{l}\text { Cochrane Database of Systematic Reviews \& } \\
\text { Cochrane Controlled Trials Register, Medline, } \\
\text { Embase, CINAHL, Web of Sciences, Ahmed, } \\
\text { Psychlit/PsychINFO, PEDRO Database of } \\
\text { Physiotherapy evidence, and other sources } \\
\text { identified in primary searches }\end{array}$ \\
\hline Handsearches & $\begin{array}{l}\text { Journals not entered on any of the above } \\
\text { electronic sources (e.g. some professional } \\
\text { journals and reference list scanning) }\end{array}$ \\
\hline Unpublished studies & $\begin{array}{l}\text { System for the Information on Grey Literature } \\
\text { in Europe (SIGLE), the Index of Conference } \\
\text { Proceedings (OCLC Firstsearch) and the British } \\
\text { PhD Theses database }\end{array}$ \\
\hline Bibliographies & $\begin{array}{l}\text { retrieved papers were scanned and examined for } \\
\text { relevance }\end{array}$ \\
\hline Research in Progress & $\begin{array}{l}\text { National Research Register, the SDO and DOH } \\
\text { research registers, Medical Research Council } \\
\text { Register, Current Research in Britain (CRIB), } \\
\text { Current Controlled Trials (www.Controlled- } \\
\text { trials.com), HSRProj (current USA projects) }\end{array}$ \\
\hline Personal contact & $\begin{array}{l}\text { With membership of professional bodies, and } \\
\text { requests for information to relevant electronic } \\
\text { mail and usenet discussion groups }\end{array}$ \\
\hline Personal contact & $\begin{array}{l}\text { with key researchers and practitioners in the } \\
\text { field via email lists, professional interest groups } \\
\text { and by informing people about the project } \\
\text { (including setting up a website) } \\
\text { http://www.sohp.soton.ac.uk/shprs/index.htm }\end{array}$ \\
\hline
\end{tabular}


Table 2 Number of different information sources located

\begin{tabular}{|l|l|}
\hline Type of resource & Number (\%) \\
\hline Audit & $47(31 \%)$ \\
\hline Letter & $18(12 \%)$ \\
\hline Service description & $17(11 \%)$ \\
\hline Survey & $12(8 \%)$ \\
\hline Newspaper / magazine article & $10(7 \%)$ \\
\hline Briefing paper & $9(6 \%)$ \\
\hline Report & $7(5 \%)$ \\
\hline Point of view / opinion piece & $7(5 \%)$ \\
\hline Case report / study & $4(3 \%)$ \\
\hline Discussion paper & $4(3 \%)$ \\
\hline Qualitative research & $4(3 \%)$ \\
\hline Non-systematic synthesis & $3(2 \%)$ \\
\hline Guideline & $2(1 \%)$ \\
\hline Theoretical paper & $2(1 \%)$ \\
\hline Cohort study & $2(1 \%)$ \\
\hline Randomised Controlled Trial & $1(0.6 \%)$ \\
\hline Conference presentation & $1(0.6 \%)$ \\
\hline Pragmatic trial & $1(0.6 \%)$ \\
\hline Dissertation & $1(0.6 \%)$ \\
\hline
\end{tabular}


Table 3 Type of Extended Scope of Practice described in the literature

\begin{tabular}{|l|l|l|}
\hline Type of intervention & $\begin{array}{l}\text { Number } \\
\text { of } \\
\text { resources }\end{array}$ & Examples $^{\text {b }}$ \\
\hline Non-invasive assessment & 71 & $\begin{array}{l}\text { Physiotherapists assessing (and managing) patients } \\
\text { with mechanical low back pain, foot and shoulder } \\
\text { disorders(35) } \\
\text { Physiotherapy extended scope practitioners } \\
\text { in orthopaedic outpatient clinics assessing and } \\
\text { diagnosing patients (12) }\end{array}$ \\
\hline Invasive assessment & 7 & $\begin{array}{l}\text { Physiotherapists referring patients for arthroscopy } \\
\text { of the knee(36) }\end{array}$ \\
\hline Non-invasive treatment & 56 & $\begin{array}{l}\text { Physiotherapists managing paediatric } \\
\text { rheumatology and orthopaedic patients(37;38) }\end{array}$ \\
\hline Invasive treatment & 23 & $\begin{array}{l}\text { ESP physiotherapists can inject, refer patient for } \\
\text { further investigations or list them for surgery(39) } \\
\text { Physiotherapists prescribe medication (40) }\end{array}$ \\
\hline $\begin{array}{l}\text { Direct access to therapist } \\
\text { rather than consultant service }\end{array}$ & 13 & $\begin{array}{l}\text { Physiotherapists forming part of the A\&E triage } \\
\text { team seeing patients as emergencies(41) } \\
\text { Initial assessment and management undertaken by } \\
\text { post-Fellowship junior orthopaedic surgeons, or by } \\
\text { specially trained physiotherapists working in an } \\
\text { extended role (orthopaedic physiotherapy } \\
\text { specialists)(9) }\end{array}$ \\
\hline
\end{tabular}

\footnotetext{
${ }^{a}$ These categories are not mutually exclusive. In some settings physiotherapists engage in all these five types of activities simultaneously. Therefore the totals add up to $>152$.

${ }^{\mathrm{b}}$ The cited examples did not pass quality criteria and should not be seen as evidence of impact but rather as examples of types of ESP activities.
} 
Table 4 Resources grouped into categories of support for ESP

\begin{tabular}{|l|l|}
\hline Level of support for ESP & $\begin{array}{l}\text { Number of } \\
\text { resources } \\
(\%)\end{array}$ \\
\hline A: Evidence (but limits to that evidence) to support ESP is provided & $16(11 \%)$ \\
\hline B: Largely descriptive / discursive but author(s) supportive of ESP & $115(76 \%)$ \\
\hline $\begin{array}{l}\text { D: Largely descriptive /discursive author(s) express concerns or are not } \\
\text { supportive of ESP }\end{array}$ & $2(1 \%)$ \\
\hline $\begin{array}{l}\text { E: Largely descriptive /discursive author(s) express partial support but also } \\
\text { concerns }\end{array}$ & $15(10 \%)$ \\
\hline
\end{tabular}
${ }^{\text {a }}$ Four resources were not scored: three were briefing papers by the Chartered Society of Physiotherapy and
one was an advisory paper (USA) on liability insurance 


\section{References}

(1) Department of Health. A compendium of solutions to implementing the Working Time Directive for doctors in training from August 2004. London: Department of Health; 2004.

(2) Department of Health. Creating a patient-led NHS: Delivering the NHS Improvement Plan. 2005.

(3) Department of Health. Meeting the challenge: a strategy for the allied health professions. London: Department of Health; 2000.

(4) Department of Health. The Chief Health Professions Officer's Ten Key Roles for allied health professionals. London: Department of Health; 2004.

(5) The Chartered Society of Physiotherapy. ESP Clinical Interest Group. http://www.csp.org.uk/director/groupandnetworks/ciogs/occupationalgroups/extend edscopepractitioners.cfm Accessed January 2007.

(6) The Chartered Society of Physiotherapy. Information paper PA 29. Chartered Physiotherapists working as extended scope practitioners (ESP). London; 2002.

(7) Sibbald B, Shen J, McBride A. Changing the skill-mix of the health care workforce. Journal of Health Services \& Research Policy 2004;9(Suppl 1):28-38.

(8) Atkins E. Physiotherapists' experience of implementing their injection therapy skills. Physiotherapy 2003;89(3):145-57.

(9) Daker-White G, Carr AJ, Harvey I, Woolhead G, Bannister G, Nelson I, et al. A randomised controlled trial. Shifting boundaries of doctors and physiotherapists in orthopaedic outpatient departments. Journal of Epidemiology and Community Health 1999;53(10):643-50.

(10) Department of Health. The NHS Plan: a plan for investment, a plan for reform. London: Department of Health; 2000.

(11) McPherson K, Kersten P, George S, Lattimer V, Breton A, Ellis B, et al. A systematic review of evidence about extended roles for Allied Health Professionals. Journal of Health Services Research and Policy 2006;11(4):240-7.

(12) Dawson LJ, Ghazi F. The experience of physiotherapy extended scope practitioners in orthopaedic outpatient clinics. Physiotherapy 2004;90(4):210-6.

(13) Ellis B, Kersten P. An exploration of the developing role of hand therapists as extended scope practitioners. British Journal of Hand Therapy 2001;6(4):126-30. 
(14) Ellis B, Kersten P. The Developing Role of Hand Therapists within the hand Surgery and Medicine services: an Exploration of Doctors' Views. British Journal of Hand Therapy 2002;7(4):119-23.

(15) Hattam P. Effectiveness of secondary referral by extended scope physiotherapists. MSc Dissertation - obtained from the Chartered Society of Physiotherapy. 2002.

(16) Milligan J. Physiotherapists working as extended scope practitioners. British Journal of Therapy \& Rehabilitation 2003;10(1):6-11.

(17) Oxford Centre for Evidence-Based Medicine. Focusing clinical questions. www.cebm.net/focus quest.asp Accessed January 2007.

(18) Public Health Resource Unit. Critical Appraisal Skills Programme (CASP) and Evidence-based Practice. http://www.phru.nhs.uk/casp/casp.htm Accessed January 2007.

(19) Centre for Reviews and Dissemination. Review Methods and Resources. http://www.york.ac.uk/inst/crd/crdreview.htm Accessed January 2007.

(20) McPherson K, Kersten P, George S, Lattimer V, Ellis B, Breton A, et al. Extended Roles for Allied Health Professionals in the NHS. NCCSDO; 2004. http:/www.sdo.1shtm.ac.uk/files/project/31-final-report.pdf

(21) Maddison P, Jones J, Breslin A, Barton C, Fleur J, Lewis R, et al. Improved access and targeting of musculoskeletal services in northwest Wales: targeted early access to musculoskeletal services (TEAMS) programme. BMJ 2004;329(7478):1325-7.

(22) Hattam P, Smeatham A. Evaluation of an orthopaedic screening service in primary care. Clin Perform Qual Health Care 1999;7(3):121-4.

(23) The Royal Orthopaedic Hospital NHS Trust. Audit of GP's opinions on the management of low back pain. 2002.

(24) Cohen J. Prescribing - your feedback. HORIZON (ESP Newsletter) 11 (July 2002), 12-13. 2002.

(25) Pearse EO, Maclean A, Ricketts DM. The extended scope physiotherapist in orthopaedic out-patients - An audit. Annals of the Royal College of Surgeons of England 2006;88(7):653-5.

(26) McClellan CM, Greenwood R, Benger JR. Effect of an extended scope physiotherapy service on patient satisfaction and the outcome of soft tissue injuries in an adult emergency department. Emergency Medicine Journal 2006;23(5):384-7.

(27) Hattam P. The effectiveness of orthopaedic triage by extended scope physiotherapists. Clinical Governance: an International Journal 2004;9(4):244-52. 
(28) Pauli R, Hammond S, Cooke J, Ansell J. Radiographers as film readers in screening mammography: an assessment of competence under test and screening conditions. The British Journal of Radiology 1996;69:10-4.

(29) Medical Research Council. A Framework for Development and Evaluation of RCTs for Complex Interventions to Improve Health. London: Medical Research Council; 2000 .

(30) Pedley DK, Bissett K, Connolly EM, Goodman CG, Golding I, Pringle TH, et al. Prospective observational cohort study of time saved by prehospital thrombolysis for ST elevation myocardial infarction delivered by paramedics. BMJ 2003;327:226.

(31) Berman L, deLacey G, Twomey E, Twomey B, Welch T, Eban R. Reducing errors in the accident department: a simple method using radiographers. BMJ $1985 ; 290: 421-2$.

(32) Hughes H, Hughes K, Hamill R. A study to evaluate the introduction of a pattern recognition technique for chest radiographs by radiographers. Radiography 1996;2(4):263-88.

(33) Bissell RA, Seaman KG, Bass RR, Racht E, Gilbert C, Weltge AF, et al. Change the scope of practice of paramedics? An EMS/public health policy perspective. Prehosp Emerg Care 1999;3(2):140-9.

(34) Department of Health. Taking Healthcare to the Patient Transforming NHS Ambulance Services. London: Department of Health; 2005.

(35) Weale AE, Bannister GC. Who should see orthopaedic outpatients -physiotherapists or surgeons? Ann R Coll Surg Engl 1995;77(2 Suppl):71-3.

(36) Gardiner J, Turner P. Accuracy of clinical diagnosis of internal derangement of the knee by extended scope physiotherapists and orthopaedic doctors: Retrospective audit. Physiotherapy 2002;88(3):153-7.

(37) Campos AA, Graveline C, Ferguson J, Feldman BM, Shneider R, Laxer RM. The physical therapy practitioner (PTP) in pediatric rheumatology: High level of patient and parent satisfaction with services. Physiotherapy Canada 2002;54(1):32-6.

(38) Reid J. An orthopaedic PT in extension. Therapy 2002 May 23;28(45):4.

(39) Cohen J. ESPs -- extending our skills. Physiotherapy Frontline 2002;Boundaries Suppl. Series 3(No. 2):8-9.

(40) The Chartered Society of Physiotherapy. Information paper PA 58. Prescribing rights for physiotherapists: an update. 2005.

(41) Oliveck M. A\&E is the place to be. Therapy 2000;27(20):4. 